SCIREA Journal of Clinical Medicine

ISSN: 2706-8870

http://www.scirea.org/journal/CM

June 8, 2021

Volume 6, Issue 3, June 2021

\title{
Characterization of Carbapenemases, Extended spectrum beta-lactamases, AmpC, Quinolone resistance and Aminoglycoside resistance determinants in Carbapenem -resistant Enterobacteriaceae clinical isolates in Mainland, \\ China
}

\author{
Huijuan Chen ${ }^{1,2}$, Qiqi Liu ${ }^{2}$, Gang Wu ${ }^{3}$, Shengqi Wang, \\ ${ }^{1}$ College of Life Sciences \& Bio-Engineering, Beijing University of Technology, Beijing \\ 100124, China. \\ ${ }^{2}$ Institute of Radiation Medicine, Beijing 100850, China. \\ ${ }^{3}$ College of Animal Science and Technology, Guangxi University, Nanning 530005, China
}

\begin{abstract}
:
Carbapenem-reistant enterobacteriaceae (CRE) have been significant increasing recently and are highly endemic in China. Several studies demonstrated the prevalence of antibiotic resistance determinants (ARD) in CRE clinical isolates, but there was no comprehensive overview based on ARDs among CRE clinical isolates in Mainland, China. The objectives of this study was assess the prevalence and distribution pattern of carbapenemase genes, ESBL genes, AmpC-encoding genes, aminoglycoside resistant genes and PMQR among CRE clinical isolates in Mainland, China. A systematic literature review was performed by
\end{abstract}


searching different electronic databases including: Pubmed, Embase, CNKI, Wanfang and CQVIP. A random effect model was used to perform the meta-analysis based on comprehensive meta-analysis software.43 studies were included in this meta-analysis. The pooled prevalence of Carbapenemase genes, ESBL genes, AmpC-encoding genes, aminoglycoside resistance genes and PMQR genes in CRE clinical isolates of Mainland, China were $73.3 \% \quad(95 \% \quad \mathrm{CI}=63.4-81.3), \quad 81.8 \% \quad(95 \% \mathrm{CI} \quad=74.3-87.4), \quad 32.7 \% \quad(95 \%$ $\mathrm{CI}=18.6-50.9), 60.6 \%(95 \% \mathrm{CI}=47.4-72.4)$ and $70.8 \%(95 \% \mathrm{CI}=60.9-79)$, respectively. $\mathrm{KPC}$ (26.1\%, 95\%CI=18.1-36.1) was the most common type in Carbapenemase genes, followed by NDM (18.4\%, 95\% CI=12.2-26.7). KPC-2 (26.6\%, 95\% CI=18.3-36.9), NDM-1 (14\%, 95\% $\mathrm{CI}=9.4-20.1), \mathrm{IMP}-4(10.6 \%, 95 \% \mathrm{CI}=6.6-16.6), \mathrm{VIM}-1 \quad(6.1 \%, 95 \% \mathrm{CI}=3.3-11.3)$ and OXA-1 $(9.8 \%, 95 \% \mathrm{CI}=3.1-27.3)$ were the predominant type of a wide range of KPC, NDM, IMP, VIM and OXA variant genes. CTX-M-15 (32.2\%, 95\%CI= 20.1-47.1), SHV-12 (23.2\%, $95 \% \mathrm{CI}=16.5-31.5)$ and TEM-1 $(54.5 \%, 95 \% \mathrm{CI}=40-68.2)$ were the main type of CTX-M, SHV and TEM-1 variant genes. CMY-42 (17.1\%, 95\% CI=5.0-44.7), aac(6')-Ib (49.0\%, 95\% $\mathrm{CI}=36.4-61.6)$ and aac(6')-Ib-cr $(37.5 \%, 95 \% \mathrm{CI}=25.5-51.4)$ was the most frequently type of AmpC-encoding, aminoglycoside resistance and PMQR genes, respectively. KPC-2, TEM-1, CMY-42, aac(6')-Ib and aac(6')-Ib-cr were the most common type of Carbapenemase genes, ESBL genes, AmpC-encoding genes, aminoglycoside resistance genes and PMQR genes.

Keywords: Carbapenemases, ESBL, AmpC, Aminoglycosides, Fluoroquinolones, Carbapenem-resistant enterobacteriaceae

\section{Introduction:}

Carbapenem-reistant enterobacteriaceae (CRE) are within the top tier of the World Health Organization (WHO) list of antibiotic-resistant "priority pathogens" that have emerged as the greatest threat to public health worldwide [1]. CRE are defined as enterobacteria non-susceptible to any carbapenem antimicrobial or documented to produce a carbapenemas [2].These bacteria are common pathogens causing a variety of severe infections such as 
ventilator-associated pneumonia(VAP), hospital-acquired pneumonia(HAP), community-acquired pneumonia (CAP), complicated urinary tract infections (cUTIs), complicated intra-abdominal infections (cIAIs) and bloodstream infections(BSIs). In China, CRE have been identified in almost every province $[3,4]$ and the prevalence of CRE has been significant increasing recently $[5,6]$.

Severe infections caused by CRE lead to prolonged hospital stays and mortality rates as high as $50 \%$ in some reports [7-10]. Treatment of CRE infections is considered as a major problem for physician due to the complex antibiotic resistance mechanisms documented in these bacteria. In CRE, there are often concomitant carriage of a myriad resistant determinants including carbapenemases, extended-spectrum $\quad \beta$-lactamases(ESBL), AmpC cephalosporinases (AmpC) associated with broad spectrum cephalosporin resistance, 16S rRNA methylases associated with resistance to aminoglycosides and plasmid-mediated quinolone resistance genes(PMQR), associated with quinolone resistance [11]. The precise molecular characterization of CRE can impact therapeutic decisions, i.e. Avibactam inhibits both Class A KPC and Class D OXA-48 [12], while relebactam and Vaborbactam inhibits only class A KPC [14,15]; plazomicin, a marketed aminoglycoside, is active against most CREs except strains producing New Delhi metallo- $\beta$-lactamases and co-expressing specific 16S rRNA methylases (ArmA and RmtC) [13]. Beside the usefulness in clinical practice, determination of the prevalence of the antibiotic resistance determinants in CRE can aid in developing rational antimicrobial therapy and infection control. In China, the prevalence of Capapenemases genes, ESBL genes, AmpC-encoding genes, aminoglycoside resistance genes and PMQR genes have been reported in several reports $[3-4,16]$. However, most of these studies only reported the data based on one hospital or local or one type resistance genes, and no systematic study has yet been published. The aim of this study was to assess the prevalence and distribution pattern of Carbapenemase, ESBL, AmpC, aminoglycoside resistant and PMQR genes among CRE clinical isolates in Mainland, China using a systematic review and meta-analysis. This information might help in designing of national strategies to control the spread of these resistance determinants in Mainland China. 


\section{Materials and Methods}

\subsection{Search strategy:}

We searched published studies in the following electronic, scientific literature databases: PubMed, Embase, CNKI, cqVIP and Wanfang database. The search strategy was designed to identify articles that focused on antibiotic resistance determinants in clinical isolates of CRE in Mainland China. Various combinations of the following keywords were used, including Carbapenem-reistant enterobacteriaceae, CRE, carbapenem resistant,antibiotic resistance determinants, antibiotic resistance gene, carbapenemase gene, EBSLs, quinolone resistant, aminoglycoside resistance genes, AmpC, Extended spectrum $\beta$-lactamases and enterobacteriaceae. The last search was done on November10, 2019.

\subsection{Study selection}

All original articles reported on the antimicrobial resistance determinants of CRE clinical isolates in Mainland China were considered. Inclusion and exclusion criteria are as follow:

\section{Inclusion criteria:}

Studies with the following characteristics were included:

1) published in Chinese or English 2) publication date between 1 January 2009 and 10 November 2019 3) reported genetic antibiotic resistance determinants 4) CRE isolated from human patients clinical samples

\section{Exclusion criteria:}

Articles were excluded if:

1) Samples were not human clinical isolates 2) samples did not come from Mainland China 3) samples were not CRE 4) Publication date were not from 2009-2019 5) studies based on CRE but not related to ARD 6) Samples from different studies were repeated 7) not experimental or observational studies, such as, case reports, letter, guidelines, or case series, reviews, etc. 8) validation of molecular techniques 9) not published in English or Chinese 


\subsection{Data Extraction}

Endnote X9 (Thomson Reuters, NEWYORK, NY), a citation manager, was used to manage the retrieved articles and remove duplicated articles. The data extraction was done using a pretested and standardized format prepared in Microsoft Excel. The following data were extracted for each study: first author, publication year, study location, populations, antimicrobial susceptibility testing(AST) methods, ARD detection methods, species of CRE, sample sizes, number of strains with antibiotic resistance determinants (Carbapenemase genes, ESBL genes, AmpC-encoding genes, aminoglycoside resistance genes, PMQR) and numbers of strains with subtype of ARD.

\subsection{Data analysis}

Comprehensive Meta-analysis statistical software (Version 2.2) was used in statistical analysis. Heterogeneity between studies was assessed by Cochran's Q test and I-squared [17-19]. Considered the heterogeneities among studies, pooled prevalence of all type antibiotic resistant determinants in CRE were estimated using a random effect model. All estimated pooled prevalence were reported using 95\% confidence intervals (CIs). Relative and cumulative frequencies were used to report the overall preponderance of Carbapenemase, ESBL, AmpC-encoding, aminoglycoside resistance, PMQR in CRE. The proportion of a subtype of Carbapenemase, ESBL, AmpC-encoding, aminoglycoside resistance and PMQR genes was calculated by dividing the number of clinical isolates in which the subtype was found by the number of CRE stains in the research.

\section{Results:}

\subsection{Search and selection of studies}

1,812 articles published from 2009 to 2019 were identified from 5 electronic databases. Based on title and abstract screening, 713 articles were excluded for duplication, and 979 were excluded after title and abstract screening. Among the remaining 120 articles, 77 articles were excluded again for specific reasons (Figure1). Finally, 43 studies were included in this meta-analysis. Of the studies search and selection process was detailed in Figure 1. 


\subsection{Characteristics of included studies}

Of the 43 studies, 41studies reported on Carbapenemase genes (TableS.1), 29 on ESBL genes (TableS.2), 12 on AmpC-encoding genes (TableS.3), 11 on aminoglycoside resistance genes (TableS.4) and 14 on PMQR (TableS.5). 12 studies reported on Carbapenem resistant Klebsiella pneumonia (CRKP) [20, 31-34, 38, 41, 43, 46-47, 51, 59], 6 studies reported on Carbapenem- resistant Enterobacter cloacae (CRECL) [22, 27, 44-45, 58], 5 studies reported on Carbapenem-resistant Escherichia coli (CRECO) [26, 36-37, 50, 55] and 1 study reported on Proteus mirabilis [57], the other studies reported on a group of Enterobacteriaceae. For resistance gene detection methods, all studies were based on PCR/Sequencing, except 3 studies based on whole genome sequencing [24, 34, 36 ].

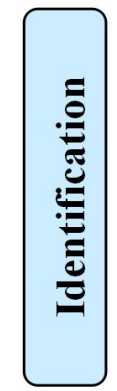

Records identified through database

searching $(\mathrm{n}=1812)$

-PubMed (535)

-Embase ( 649)

-Chinese databases (CNKI, Wangfang data and CQVIP, $n=628$ )
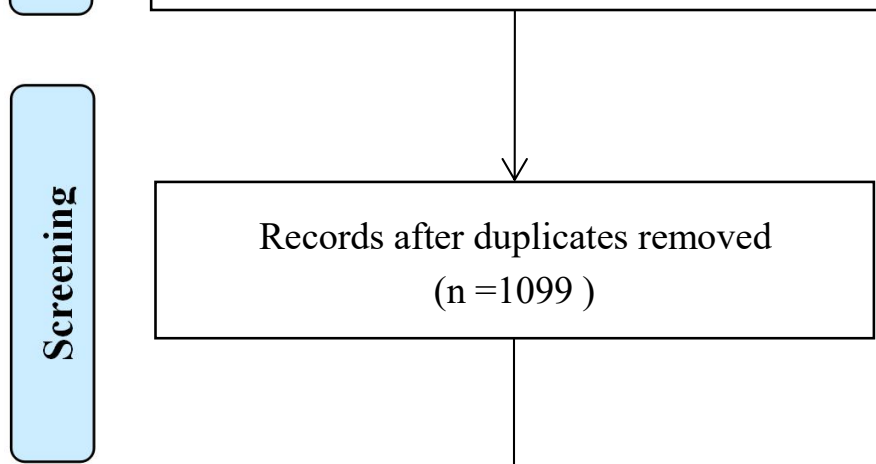

979 Records excluded after screening the titles and abstracts

-report not related to antibiotic resistance genes $(\mathrm{n}=573)$

-Editorials/letters/case report/reviews $(n=149)$

-Reports not on human $(\mathrm{n}=119)$

-study not in Mainland China $(n=55)$

-reports not on clinical isolates $(n=40)$

-Reports not on CRE( $(n=43)$

Full-text articles assessed for eligibility $(\mathrm{n}=120)$
77 Full-text articles excluded with reasons - Study not in Mainland China $(n=10)$

- Reports not related to antibiotic resistance genes $(n=5)$

-studies used the same samples $(\mathrm{n}=2)$

-Case report/reviews ( $\mathrm{n}=9$ )

-Reports not on CRE ( $\mathrm{n}=36$ )

-Reports not on human/clinical isolates $(\mathrm{n}=8)$

-Reports on molecular techniques

$218 \quad$ validation $(\mathrm{n}=5)$

-Reports published in language other than English or Chinese $(\mathrm{n}=2)$ 
Studies included in quantitative synthesis

(meta-analysis)

$(n=43)$

Figure 1. Flow chart of search and selection studies. CNKI: China National Knowledge Infrastructure; CQVIP: Chongqing VIP

\subsection{Pooled antibiotic resistance genes proportions}

The pooled proportions of Carbapenemase genes in $\mathrm{CRE}$ was $73.3 \%$ (95\% $\mathrm{CI}=63.4-81.3$; $\mathrm{I}^{2}=94.16$; $\mathrm{Q}=684.61(P=0)$; Figuare $\left.2 \mathrm{~A}\right)$; The pooled proportions of ESBL genes in CRE was 81.8\% $\left(95 \% \mathrm{CI}=74.3-87.4 ; \mathrm{I}^{2}=86.80 ; \mathrm{Q}=212.1(P=0)\right.$; Figuare $\left.2 \mathrm{~B}\right)$; The pooled proportions of AmpC-encoding genes in $\mathrm{CRE}$ was 32.7\% (95\% CI=18.6-50.9; $\mathrm{I}^{2}=94.49 ; \mathrm{Q}=199.80(P=0)$; Figuare 2C); The pooled proportions of aminoglycoside resistance genes in CRE was $60.6 \%$ (95\% CI=47.4-72.4; $\mathrm{I}^{2}=81.71 ; \mathrm{Q}=54.689(P=0)$; Figuare 2D); The pooled proportion of PMQR genes in CRE was 70.8\%( 95\% $\mathrm{CI}=60.9-79 ; \mathrm{I}^{2}=76.34 ; \mathrm{Q}=54.94(P=0)$; Figuare $\left.2 \mathrm{E}\right)$. 


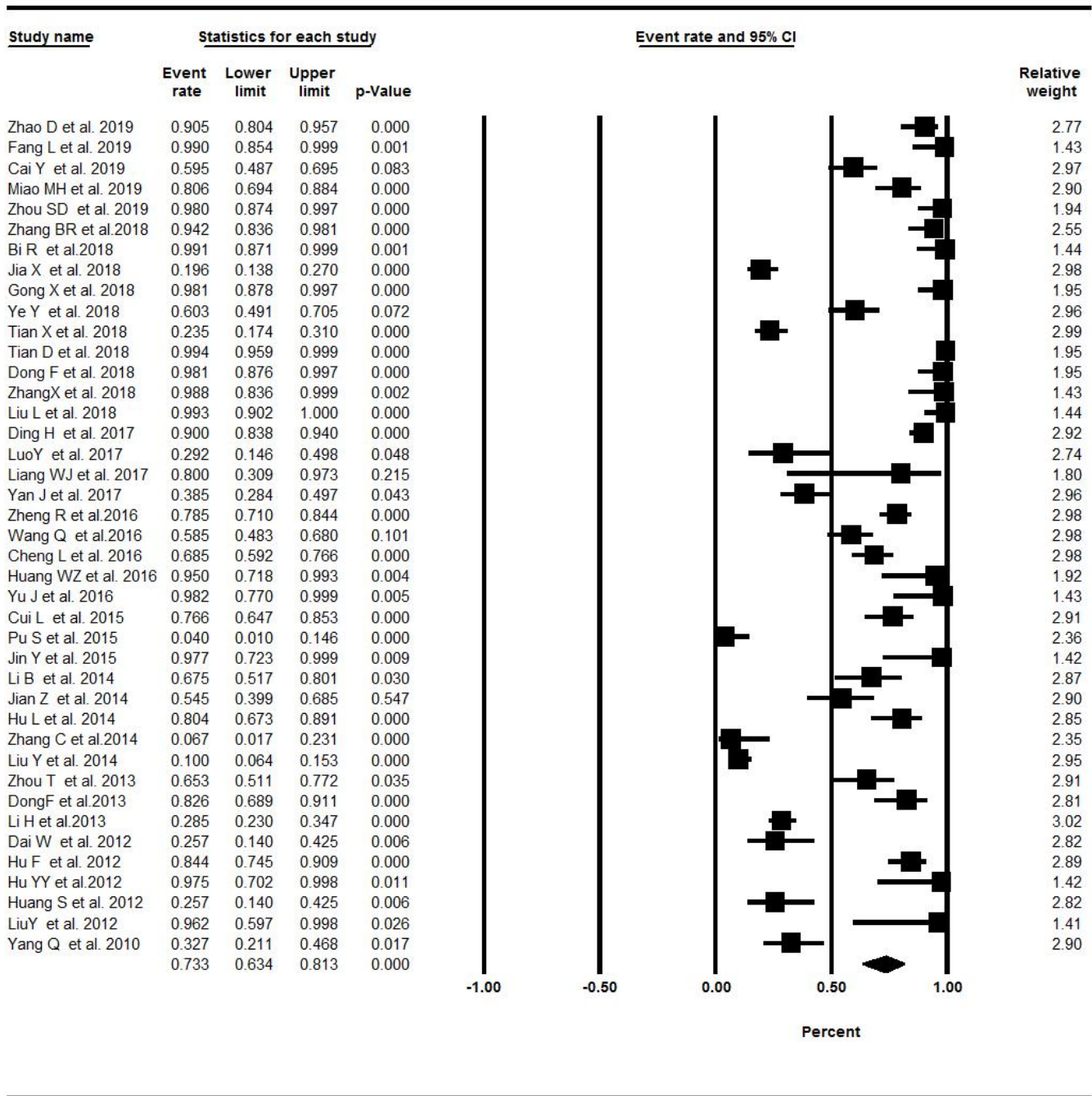

Random effects model, $p=0$; Cochran's $Q=684.61, I$ square $=94.16$ 


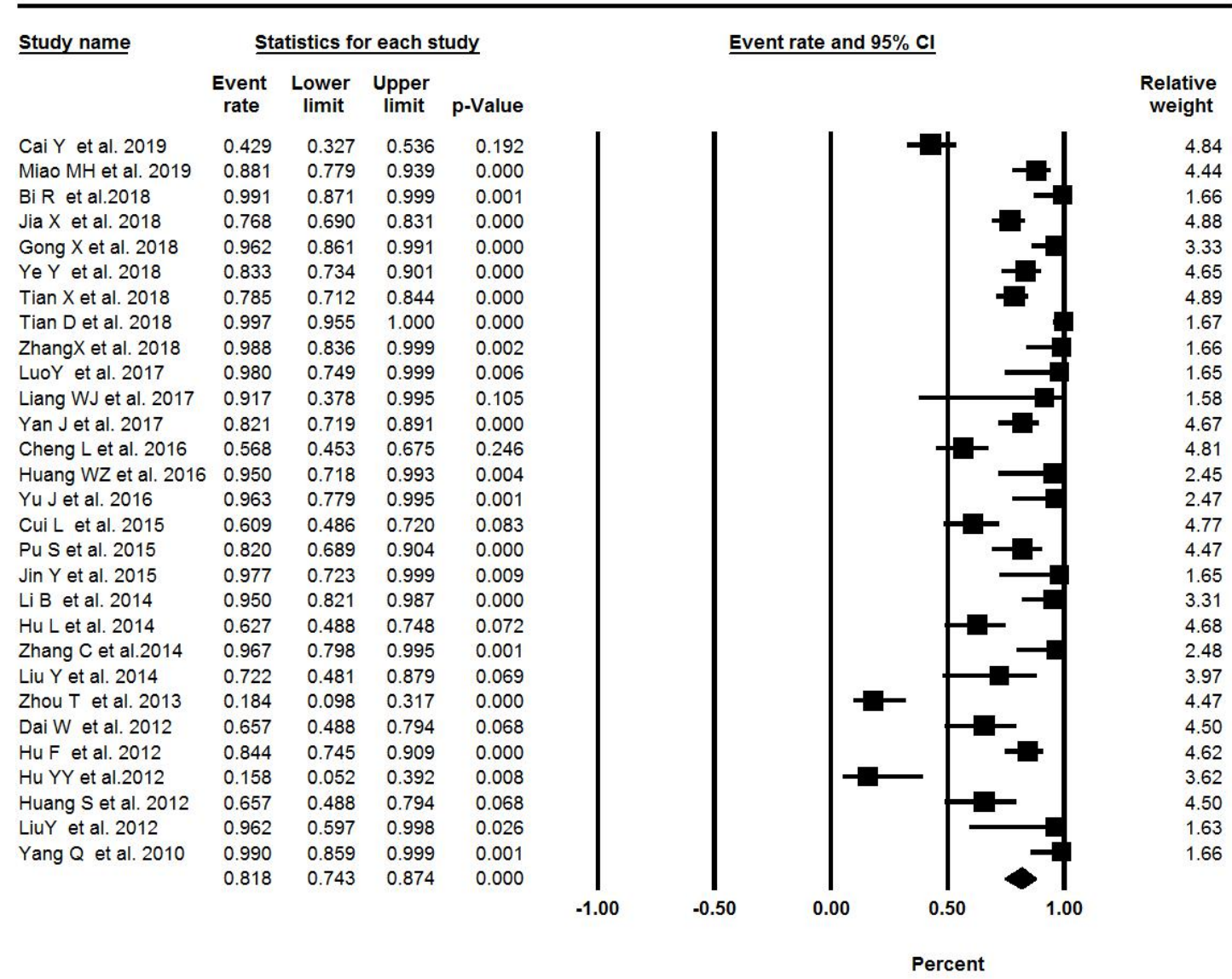

Random effects model, $p=0$; Cochran's $Q=212.1$, I square $=86.8$ C

AmpC-encoding Genes

Study name

$\begin{array}{lcccr} & \begin{array}{c}\text { Event } \\ \text { rate }\end{array} & \begin{array}{c}\text { Lower } \\ \text { limit }\end{array} & \begin{array}{c}\text { Upper } \\ \text { limit }\end{array} & \text { p-Value } \\ \text { Miao MH et al. 2019 } & 0.433 & 0.320 & 0.553 & 0.273 \\ \text { Bi R et al.2018 } & 0.222 & 0.131 & 0.352 & 0.000 \\ \text { Jia X et al. 2018 } & 0.855 & 0.786 & 0.905 & 0.000 \\ \text { Ye Y et al. 2018 } & 0.397 & 0.295 & 0.509 & 0.072 \\ \text { Tian D et al. 2018 } & 0.053 & 0.028 & 0.099 & 0.000 \\ \text { ZhangX et al. 2018 } & 0.146 & 0.067 & 0.290 & 0.000 \\ \text { Liu J et al. 2018 } & 0.094 & 0.048 & 0.177 & 0.000 \\ \text { LuoY et al. 2017 } & 0.333 & 0.176 & 0.539 & 0.109 \\ \text { Yan J et al. 2017 } & 0.474 & 0.367 & 0.585 & 0.651 \\ \text { Jin Y et al. 2015 } & 0.857 & 0.639 & 0.953 & 0.004 \\ \text { Hu L et al. 2014 } & 0.255 & 0.154 & 0.391 & 0.001 \\ \text { Zhou T et al. 2013 } & 0.204 & 0.113 & 0.339 & 0.000 \\ & 0.327 & 0.186 & 0.509 & 0.061\end{array}$

\section{Event rate and $95 \% \mathrm{Cl}$}

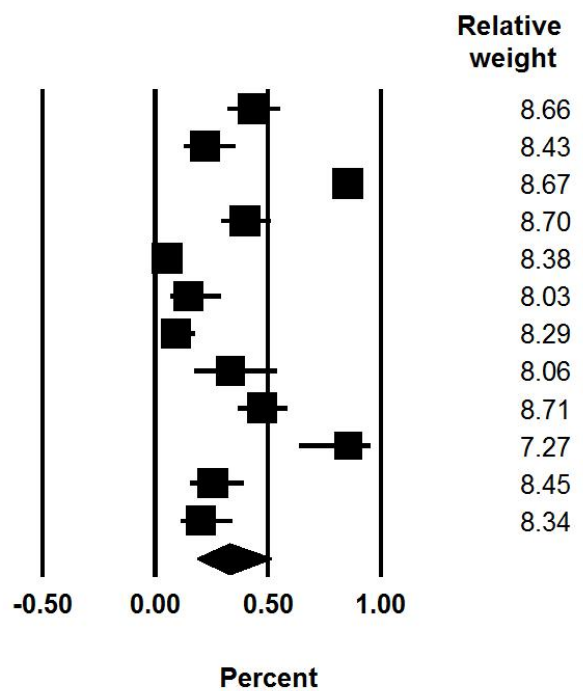

Random effects model, $p=0$; Cochran's $Q=199.8$, l square $=94.49$ 


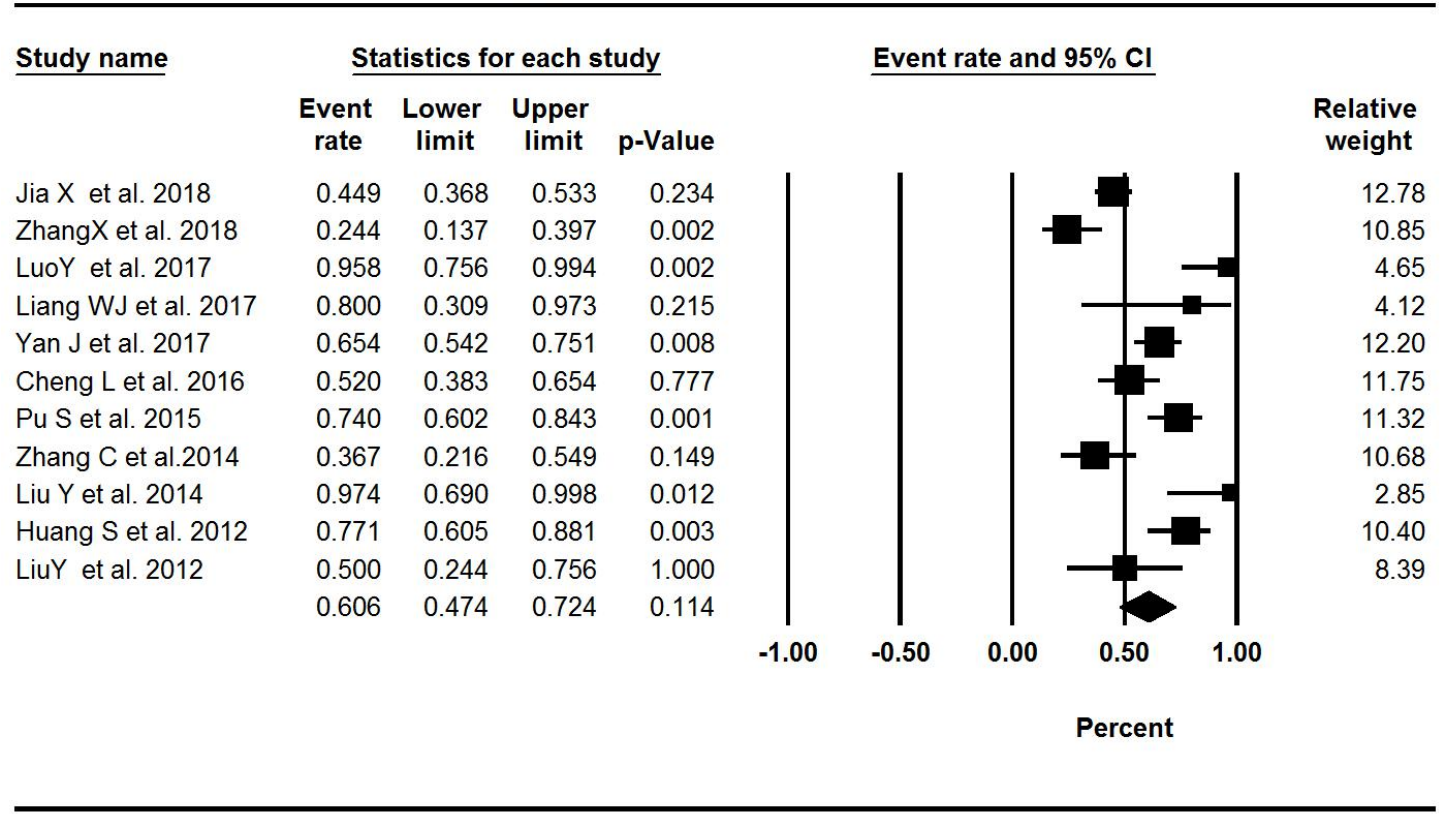

Random effects model, $p=0$; Cochran's $Q=54.68$, I square $=81.71$

E Plasmid-mediated Quinolone Resistance Genes

Study name

$\begin{array}{lcccr} & \begin{array}{c}\text { Event } \\ \text { rate }\end{array} & \begin{array}{c}\text { Lower } \\ \text { limit }\end{array} & \begin{array}{c}\text { Upper } \\ \text { limit }\end{array} & \text { p-Value } \\ \text { Su SS et al. 2019 } & 0.912 & 0.806 & 0.963 & 0.000 \\ \text { Jia X et al. 2018 } & 0.659 & 0.577 & 0.734 & 0.000 \\ \text { ZhangX et al. 2018 } & 0.976 & 0.846 & 0.997 & 0.000 \\ \text { LuoY et al. 2017 } & 0.542 & 0.346 & 0.725 & 0.683 \\ \text { Liang WJ et al. 2017 } & 0.917 & 0.378 & 0.995 & 0.105 \\ \text { Yan J et al. 2017 } & 0.782 & 0.677 & 0.860 & 0.000 \\ \text { Pu S et al. 2015 } & 0.820 & 0.689 & 0.904 & 0.000 \\ \text { Hu L et al. 2014 } & 0.627 & 0.488 & 0.748 & 0.072 \\ \text { Zhang C et al.2014 } & 0.667 & 0.484 & 0.810 & 0.074 \\ \text { Liu Y et al. 2014 } & 0.974 & 0.690 & 0.998 & 0.012 \\ \text { Hu YY et al.2012 } & 0.632 & 0.403 & 0.813 & 0.257 \\ \text { Huang S et al. 2012 } & 0.686 & 0.517 & 0.817 & 0.032 \\ \text { LiuY et al. 2012 } & 0.167 & 0.042 & 0.477 & 0.038 \\ \text { Yang Q et al. 2010 } & 0.469 & 0.335 & 0.608 & 0.668 \\ & 0.708 & 0.609 & 0.790 & 0.000\end{array}$

Event rate and $95 \% \mathrm{Cl}$

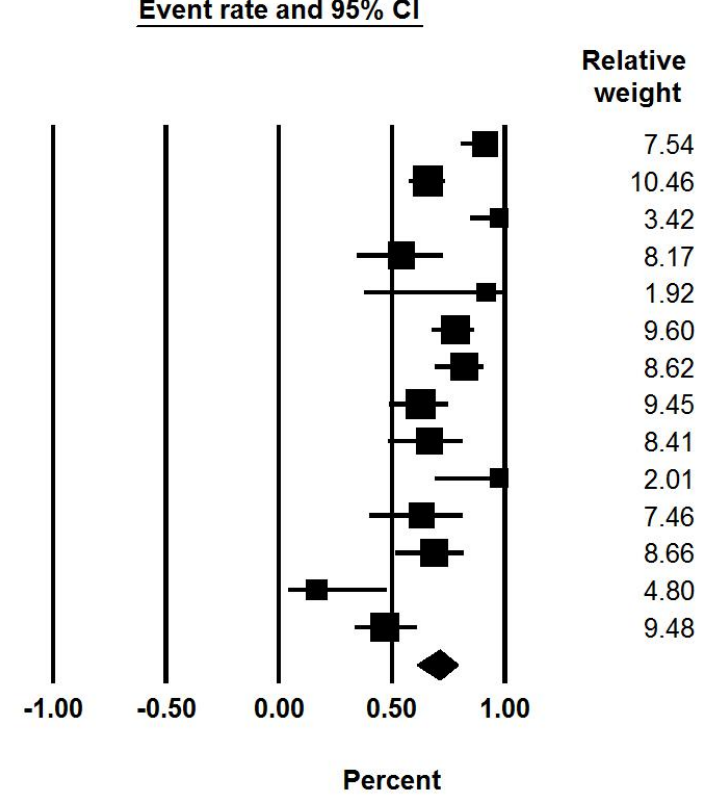

Random effects model, $\mathrm{p}=0$; Cochran's $\mathrm{Q}=54.94, \mathrm{I}$ square $=76.34$

Figure 2. Forest plots of antibiotic resistance determinants proportions in CRE clinical isolates

in Mainland China. Carbapenemase genes (A), ESBL genes (B), AmpC-encoding genes (C), aminoglycoside resistance genes (D), plasmid-mediated quinolone resistance genes $(E)$. 


\subsection{Preponderance of Carbapenemase genes}

Of the Carbapenemase genes, KPC, NDM, IMP, VIM, OXA and GIM but GES (0/929) [24-26, $32-34,36,39,41-43,46-47,52-53,56,60], \operatorname{SME}(0 / 1060)$ [24-27, 32, 34, 36, 38, 41-42, 45-47, 50, 52-53, 56, 58-60] have been identified (Table1). The pooled prevalence of KPC, NDM, IMP, VIM, OXA and GIM among CRE, respectively, were $26.1 \%(95 \% \mathrm{CI}=18.1-36.1), 18.4 \%$ $(95 \% \quad \mathrm{CI}=12.2-26.7), \quad 11.2 \% \quad(95 \% \quad \mathrm{CI}=7.8-15.8), \quad 1.8 \% \quad(95 \% \quad \mathrm{CI}=1.2-2.7), \quad 2.2 \% \quad(95 \%$ $\mathrm{CI}=1.0-4.5), 3.9 \%(95 \% \mathrm{CI}=0.7-18.3) . K P C-2(26.6 \%, 95 \% \mathrm{CI}=18.3-36.9)$ was the most frequently type in KPC, NDM-1 $(14 \%, 95 \% \mathrm{CI}=9.4-20.1)$ in $N D M, I M P-4(10.6 \%, 95 \% \mathrm{CI}=$ 6.6-16.6) in $\operatorname{IMP}, \operatorname{VIM}-1(6.1 \%, 95 \% \mathrm{CI}=3.3-11.3)$ in $V I M, O X A-1 \quad(9.8 \%, 95 \% \mathrm{CI}=3.1-27.3)$ in $O X A$ if all single study omitted. No $O X A-48(0 / 1708)$ has been identified in CRE.

Table1. Relative and cumulative frequencies of Carbapenemase genes

\begin{tabular}{|c|c|c|c|c|c|}
\hline \multirow{2}{*}{ Genotype } & \multirow{2}{*}{$\mathbf{N}$} & \multicolumn{3}{|c|}{$\mathrm{P}(95 \% \mathrm{CI}) *$} & \multirow{2}{*}{ References } \\
\hline & & $P$ & $\mathrm{~L}$ & $\mathrm{U}$ & \\
\hline KPC & 2834 & 26.1 & 18.1 & 36.1 & {$[20-60]$} \\
\hline$K P C-2$ & 2786 & 26.6 & 18.3 & 36.9 & {$[20-24,26-36,38-60]$} \\
\hline$K P C-3$ & 46 & 2.2 & 0.3 & 13.9 & [23] \\
\hline$N D M$ & 2182 & 18.4 & 12.2 & 26.7 & {$[20-28,30-35,38-41,43,44,47,49,51,52,55,56]$} \\
\hline$N D M-1$ & 2182 & 14 & 9.4 & 20.1 & {$[20-28,30-35,38-41,43,44,47,49,51,52,55,56]$} \\
\hline$N D M-4$ & 54 & 3.7 & 0.9 & 13.6 & {$[26]$} \\
\hline$N D M-5$ & 736 & 9.2 & 3.6 & 21.6 & {$[23,24,26,28,30,31,34,36,40]$} \\
\hline$N D M-7$ & 201 & 3.3 & 0.7 & 13.5 & {$[26,28,40]$} \\
\hline$N D M-9$ & 105 & 3 & 1.0 & 9.0 & {$[24,26]$} \\
\hline IMP & 2824 & 11.2 & 7.8 & 15.8 & {$[20-56,58-60]$} \\
\hline$I M P-1$ & 886 & 2.8 & 1.5 & 5.2 & {$[22,29,35,36,39,44,54,56]$} \\
\hline$I M P-2$ & 155 & 6.5 & 3.5 & 11.6 & {$[29,56]$} \\
\hline
\end{tabular}




\begin{tabular}{|c|c|c|c|c|c|}
\hline$I M P-4$ & 2114 & 10.6 & 6.6 & 16.6 & {$[22-24,27,28,30-36,38-40,42,43,46-49,51-54,60]$} \\
\hline$I M P-8$ & 987 & 6.1 & 3.7 & 9.8 & {$[27,28,30,44,45,47,49,52-55,58,60]$} \\
\hline IMP-26 & 205 & 6.2 & 3.1 & 12.2 & {$[22,49,55,58]$} \\
\hline IMP-38 & 107 & 9.1 & 1.3 & 42.9 & {$[20,48]$} \\
\hline$V I M$ & 2279 & 1.8 & 1.2 & 2.7 & {$[20-29,31-33,35-39,41-53,55,56,58-60]$} \\
\hline$V I M-1$ & 302 & 6.1 & 3.3 & 11.3 & {$[23,28,29,43,56]$} \\
\hline$V I M-2$ & 408 & 0.8 & 0.2 & 2.9 & {$[51,54]$} \\
\hline$O X A$ & 2097 & 2.2 & 1.0 & 4.5 & {$[20-39,28-31,43,46-48,51-53,56,60]$} \\
\hline$O X A-1$ & 241 & 9.8 & 3.1 & 27.3 & {$[24,30,33]$} \\
\hline$O X A-23$ & 144 & 3.5 & 1.4 & 8.5 & {$[21,24,53]$} \\
\hline$O X A-48$ & 1708 & 0 & 0 & 0 & {$[20,22-29,31-39,43,47,48,51,52]$} \\
\hline$O X A-66$ & 51 & 3.9 & 1.0 & 14.4 & {$[24]$} \\
\hline OXA-69 & 78 & 12.8 & 7.0 & 22.2 & {$[29]$} \\
\hline$O X A-232$ & 170 & 42.4 & 35.1 & 49.9 & {$[31]$} \\
\hline GIM & 891 & 2.1 & 1.2 & 3.7 & {$[24-25,29,31-32,34,36,41,46-47,52-53,56,60]$} \\
\hline
\end{tabular}

N, number; P, proportion; L, lower limit; U, upper limit; *Score confidence interval

\subsection{Preponderance of ESBL genes}

The pooled prevalence of $C T X-M, S H V$ and TEM among CRE, respectively, were $60.4 \%$ $(95 \% \mathrm{CI}=49.6-70.2), 41.0 \%(95 \% \mathrm{CI}=29.6-53.5)$ and 50.1\% (95\% CI=39.9-60.2) (Table2). $C T X-M-15(32.2 \%, 95 \% \mathrm{CI}=20.1-47.1)$ was the most frequently gene in $C T X-M$, followed by $C T X-M-14(28.5 \%, 95 \% \mathrm{CI}=19.5-39.7)$ and $C T X-M-24(19.3 \%, 95 \% \mathrm{CI}=2.3-71) ; S H V-12$ (23.2\%, 95\% CI=16.5-31.5) was the most frequently gene in $S H V$, followed by $S H V-11$ $(20.7 \%, 95 \% \mathrm{CI}=8.8-41.4) ;$ TEM-1 $(54.5 \%, 95 \% \mathrm{CI}=40-68.2)$ was the most frequently gene in TEM. 
Table2. Relative and cumulative frequencies of ESBL genes

\begin{tabular}{|c|c|c|c|c|c|}
\hline \multirow{2}{*}{ Genotype } & \multirow{2}{*}{$\mathrm{N}$} & \multicolumn{3}{|c|}{$P(95 \% \mathrm{CI}) *$} & \multirow{2}{*}{ References } \\
\hline & & $\mathbf{P}$ & $\mathbf{L}$ & $\mathbf{U}$ & \\
\hline CTXM & 1474 & 60.4 & 49.6 & 70.2 & {$[22-23,26,28,29-31,33,36-38,41-47,49-52,55-60]$} \\
\hline$C T X-M-1$ & 282 & 3.2 & 0.6 & 15.5 & {$[30,42,44,52]$} \\
\hline$C T X-M-2$ & 219 & 1.2 & 0.3 & 3.9 & {$[29,44,56]$} \\
\hline$C T X-M-3$ & 584 & 11.8 & 6.9 & 19.6 & {$[23,30,38,45,47,49,50,52,55,58]$} \\
\hline$C T X-M-9$ & 331 & 11.3 & 8.3 & 15.2 & {$[23,30,44,49]$} \\
\hline$C T X-M-14$ & 1102 & 28.5 & 19.5 & 39.7 & {$[23,26,29-31,33,36,41,43,45-47,49-52,55-56,58,59]$} \\
\hline$C T X-M-15$ & 890 & 32.2 & 20.1 & 47.1 & {$[23,26,28-29,31,33,36-38,41,43,46,47,49,51,56,59]$} \\
\hline$C T X-M-24$ & 227 & 19.3 & 2.3 & 71 & {$[30,38]$} \\
\hline$C T X-M-38$ & 74 & 2.7 & 0.7 & 10.2 & [41] \\
\hline$C T X-M-52$ & 227 & 2.9 & 0.8 & 10.2 & {$[30,38]$} \\
\hline$C T X-M-55$ & 233 & 11.3 & 2.1 & 42.6 & {$[26,30,50]$} \\
\hline$C T X-M-64$ & 54 & 1.9 & 0.3 & 12 & [26] \\
\hline$C T X-M-65$ & 212 & 13.4 & 6.1 & 27 & {$[23,26,47,49]$} \\
\hline$C T X-M-84$ & 51 & 2.0 & 0.3 & 12.6 & [49] \\
\hline$C T X-M-90$ & 54 & 1.9 & 0.3 & 12 & [26] \\
\hline$C T X-M-123$ & 54 & 1.9 & 0.3 & 12 & [26] \\
\hline SHV & 1391 & 41.0 & 29.6 & 53.5 & {$[22-23,26,28,30-31,33,36,38,41-47,49-52,55-60]$} \\
\hline$S H V-1$ & 484 & 8.5 & 1.4 & 37.5 & {$[30-31,41,47,49]$} \\
\hline$S H V-2$ & 149 & 19.5 & 13.9 & 26.6 & {$[30]$} \\
\hline$S H V-5$ & 221 & 1.1 & 0.3 & 4.2 & {$[31,49]$} \\
\hline$S H V-11$ & 555 & 20.7 & 8.8 & 41.4 & {$[30,31,33,41,47,49,51,59]$} \\
\hline
\end{tabular}




\begin{tabular}{|c|c|c|c|c|c|}
\hline$S H V-12$ & 799 & 23.2 & 16.5 & 31.5 & {$[22-23,30,31,41,44,47,49,51,55,58-59]$} \\
\hline$S H V-26$ & 189 & 6.4 & 0.7 & 40.2 & {$[30,47]$} \\
\hline$S H V-27$ & 41 & 4.9 & 1.2 & 17.5 & [33] \\
\hline$S H V-28$ & 165 & 3.2 & 1.4 & 7.5 & {$[41,47,49]$} \\
\hline$S H V-31$ & 114 & 7.2 & 3.6 & 13.7 & {$[41,47]$} \\
\hline$S H V-33$ & 40 & 5 & 1.3 & 17.9 & [47] \\
\hline$S H V-36$ & 125 & 1.6 & 0.4 & 6.3 & {$[41,49]$} \\
\hline$S H V-145$ & 40 & 2.5 & 0.4 & 15.7 & [47] \\
\hline$S H V-160$ & 74 & 2.7 & 0.7 & 10.2 & [41] \\
\hline TEM & 1534 & 50.1 & 39.9 & 60.2 & {$[22-23,26-28,30-31,33,36-38,41-47,49-52,55-60]$} \\
\hline TEM-1 & 902 & 54.5 & 40 & 68.2 & {$[22,26,30-31,33,36-37,41,43,44,46-47,49,51,57,59-60]$} \\
\hline TEM-6 & 70 & 37.1 & 26.7 & 49.0 & {$[55,58]$} \\
\hline TEM-30 & 84 & 19 & 12 & 28.9 & [22] \\
\hline
\end{tabular}

N, number; P, proportion; L, lower limit; U, upper limit; *Score confidence interval

\subsection{Preponderance of AmpC-encoding genes}

CMY-42 (17.1\%, 95\% CI=5.0-44.7) was the most frequently AmpC-encoding genes in CRE, followed by $D H A-1(12.4 \%, 95 \% \mathrm{CI}=5.2-26.8), C M Y-2(8.2 \%, 95 \% \mathrm{CI}=4.2-15.4), A C T(5.5 \%$, 95\% CI=1.3-20.1), EBC (4.1\%, 95\% CI=0.5-28.2), MIR-3 $(2.0 \%, 1 / 51)$ and $C M Y-6(1.2 \%$, 95\% CI =0.4-3.6). No FOX (0/379), MOX (0/379) and CIT (0/379) have been identified in CRE $[52,46,61,31,26]$.

Table3 Relative and cumulative frequencies of AmpC-encoding genes

\begin{tabular}{|c|c|c|c|c|c|}
\hline \multirow{2}{*}{ Genotype } & \multirow{2}{*}{$\mathbf{N}$} & \multicolumn{3}{|c|}{$P(95 \% \mathrm{CI}) *$} & \multirow{2}{*}{ References } \\
\hline & & $\mathbf{P}$ & $\mathbf{L}$ & $\mathbf{U}$ & \\
\hline$E B C$ & 541 & 4.1 & 0.5 & 28.2 & {$[26,27,31,61,36,46,52]$} \\
\hline
\end{tabular}




\begin{tabular}{cccccc} 
DHA-1 & 562 & 12.4 & 5.2 & 26.8 & {$[23,26,31,33,61,36,46,49,52]$} \\
\hline$A C T$ & 118 & 5.5 & 1.3 & 20.1 & {$[23,49]$} \\
\hline$C M Y-42$ & 78 & 17.1 & 5.0 & 44.7 & {$[26,36]$} \\
\hline$C M Y-2$ & 172 & 8.2 & 4.2 & 15.4 & {$[23,26,49]$} \\
\hline$C M Y-6$ & 255 & 1.2 & 0.4 & 3.6 & {$[41,61]$} \\
\hline$M I R-3$ & 51 & 2.0 & 0.3 & 12.6 & \\
\hline
\end{tabular}

N, number; P, proportion; L, lower limit; U, upper limit; *Score confidence interval

\subsection{Preponderance of aminoglycoside resistance genes}

Of the aminoglycoside resistance genes, aac(6')-Ib, armA, rmtB, aac(3)-IIa-like, aadA1, aadA5 and strA but $r m t A(0 / 103), r m t C(0 / 103), r m t D(0 / 103)[59,41,33]$ and $r m t E(0 / 50)$ [41] have been identified (Table4). The prevalence of $a a c\left(6^{\prime}\right)-I b, a r m A, \operatorname{rmtB}$ in CRE, respectively, were $49.0 \%(95 \% \mathrm{CI}=36.4-61.6), 8.9 \%(95 \% \mathrm{CI}=3.6-20.4)$ and $15.9 \%(95 \%$ $\mathrm{CI}=7.0-32.2)$. The frequencies of aac(3)-IIa-like, aadA1, aadA5 and strA in CRE from the single article reported, respectively, were 58.3\% (14/24), 80\% (4/5), 50.0\% (12/24) and $33.3 \%(8 / 24)$.

Table4 Relative and cumulative frequencies of aminoglycoside resistance genes

\begin{tabular}{|c|c|c|c|c|c|}
\hline \multirow{2}{*}{ Genotype } & \multirow{2}{*}{$\mathbf{N}$} & \multicolumn{3}{|c|}{$\mathbf{P}(95 \% \mathrm{CI}) *$} & \multirow{2}{*}{ References } \\
\hline & & $\mathrm{P}$ & $\mathrm{L}$ & $\mathrm{U}$ & \\
\hline$a a c\left(6^{\prime}\right)-I b$ & 399 & 49.0 & 36.4 & 61.6 & {$[27,38,41,45,50,51,58]$} \\
\hline aac(3)-IIa-like & 24 & 58.3 & 38.3 & 81.3 & {$[36]$} \\
\hline $\operatorname{aad} A 1$ & 5 & 80.0 & 30.9 & 97.3 & {$[37]$} \\
\hline $\operatorname{aad} A 5$ & 24 & 50.0 & 31 & 69 & {$[36]$} \\
\hline $\operatorname{str} A$ & 24 & 33.3 & 17.6 & 53.9 & {$[36]$} \\
\hline $\operatorname{arm} A$ & 476 & 8.9 & 3.6 & 20.4 & {$[27,33,36,38,41,45,50-51,58,59]$} \\
\hline$r m t B$ & 476 & 15.9 & 7.0 & 32.2 & {$[27,33,36,38,41,45,50-51,58,59]$} \\
\hline
\end{tabular}


N, number; P, proportion; L, lower limit; U, upper limit; *Score confidence interval

\subsection{Preponderance of PMQR genes}

Of PMQR genes, qnrA, qnrB, qnrD, qnrS, aac (6')-Ib-cr and oqxA/B but $q n r C(0 / 252)[27,33$, $36,50,57]$ and qepA $(0 / 164)[62,33,36-37,51,57]$ have been observed (Table5). The prevalence of $q n r A$, qnrB, qnrD, qnrS, aac (6')-Ib-cr and oqxA/B in CRE, respectively, were $5.9 \%(95 \% \mathrm{CI}=2.8-11.9), 27.4 \%(95 \% \mathrm{CI}=17.0-41.0), 3.3 \%(95 \% \mathrm{CI}=0.2-40.6), 22.3 \%(95 \%$ $\mathrm{CI}=14.8-32.3), 37.5 \%(95 \% \mathrm{CI}=25.5-51.4)$ and $(85.4 \%, 35 / 41)$.

Table5 Relative and cumulative frequencies of PMQR genes

\begin{tabular}{cccccc}
\hline \multirow{2}{*}{ Genotype } & $\mathrm{N}$ & \multicolumn{3}{c}{$\mathrm{P}(95 \% \mathrm{CI})^{*}$} & \\
\cline { 3 - 5 } & & $\mathrm{P}$ & $\mathrm{L}$ & $\mathrm{U}$ & References \\
\hline$q n r A$ & 607 & 5.9 & 2.8 & 11.9 & {$[62,27,23,36-38,45,49-51,57-60]$} \\
\hline$q n r B$ & 607 & 27.4 & 17.0 & 41.0 & {$[62,27,23,36-38,45,49-51,57-60]$} \\
\hline$q n r D$ & 252 & 3.3 & 0.2 & 40.6 & {$[27,33,36,50,57]$} \\
\hline qnrS & 607 & 22.3 & 14.8 & 32.3 & {$[62,27,23,36-38,45,49-51,57-60]$} \\
\hline aac (6')-Ib-cr & 607 & 37.5 & 25.5 & 51.4 & {$[62,27,23,36-38,45,49-51,57-60]$} \\
\hline oqxA/B & 41 & $85.4 \%$ & 71 & 93.3 & {$[33]$} \\
\hline
\end{tabular}

N, number; P, proportion; L, lower limit; U, upper limit; *Score confidence interval

\section{Discussion}

To our knowledge, this was the first systematic review and meta-analyses to address the prevalence of Cabapenemases, ESBL, AmpC-encoding, aminoglycoside resistant and PMQR genes among CRE clinical isolates in Mainland China. Based on the results of this study, the pooled prevalence of Carbapenemase genes in CRE clinical isolates of Mainland China was $73.3 \%(95 \% \mathrm{CI}=63.4-81.3)$, and $K P C(26.1 \%, 95 \% \mathrm{CI}=18.1-36.1)$ was the most widely spread Carbapenemase gene, followed by $\operatorname{NDM}(18.4 \%, 95 \% \mathrm{CI}=12.2-26.7)$. Our finding are similar to the previous reports by China CRE Network [3-4]. KPC-2 and KPC-3 were the 
most common type in CRE of United Stated [63]. In our study, Just KPC-2 was the most frequently type among CRE of China. To date, $N D M-1$ remains the most common NDM variant isolated in the seven NDM variants (NDM1-NDM7) [64], our study showed the similar result. At the present time, IMP-type Enterobateriaceae were mainly found in Japan and Taiwan, China [65], and IMP-1 was the most widespread type in Japan [66] but Taiwan, China with $I M P-8$ [67]. In our study, IMP-4 (10.6\%, 95\% CI=6.6-16.6) was the most common type in Mainland, China. The epicenter of VIM-type Enterobateriaceae was Greece, VIM-2 was predominate type worldwide but VIM-1 in our study same as in Greece [68]. As for $O X A$, the commonest type was $O X A-48$. OXA-48 producing CRE were mainly concentrated in Middle East (Turkey), North Africa and European countries, rare in China [69, 70]. OXA-48, as well GES and $S M E$, was not found in our study.

ESBL and plasmid encoding AmpC genes were mostly detected in CRE. In China, 45.8\% Taiwanese CRE harbored various ESBL genes (80\% were the CTX-M types) and $62.0 \%$ harbored AmpC genes (70.6\% were DHA and 22.3\% were CMY) [67]. In Mainland, $61.6 \%$ CRKP harbored ESBL genes (mainly CTX-M 65 and $C T X-M-14$ ) and 14.4\% harbored AmpC genes (DHA-1 and ACT-20) [70]. In our study, the pooled proportions of ESBL genes in CRE was $81.8 \%(95 \% \mathrm{CI}=74.3-87.4)$ and $\mathrm{AmpC}$ genes was $32.7 \%(95 \% \mathrm{CI}=18.6-50.9) . C T X-M$, $S H V$ - and TEM-type enzymes were the most clinically significant ESBL variants. CTX-M (60.4\%, 95\% CI=49.6-70.2) was the most common type, followed by TEM $(50.1 \%$, 95\% $\mathrm{CI}=39.9-60.2)$ and $S H V(41.0 \%, 95 \% \mathrm{CI}=29.6-53.5)$ among CRE in our study. $C T X-M-15$ and $C T X-M-14, S H V-12$ were the dominant CTX-M and SHV variants in enterobacteriaceae of the Asia-Pacific area [71, 72]. In China, CTX-M-14 was the most common CTX-M type but $C T X-M-15$ with a steady increase has been identified [73]. CTX-M-15, SHV-12 and TEM-1 were identified as the common ones along with a wide range of other $C T X-M$, SHV and TEM variant genes in this study. According our study, $C M Y-42$ was the most prevalent AmpC gene, followed by DHA1 among CRE in Mainland, China. But CMY-2 was the most frequently type in Enterobacteriaceae especially in E.coli worldwide [74], and the similar result was found in the study based on Asia-Pacific region [71,72].

In terms of frequency, acetyltransferases (AAC), nucleotidyltransferases (ANT), and 
phosphotransferases (APH), aminoglycoside-modifying enzymes (AMEs) are the most important determinant of aminoglycoside resistance in Enterobacteriaceae and many other Gram-negative bacteria [75]. In addition, 16S rRNA methylases is another major mechanisms of resistance to aminoglycosides in Enterobaceriaceae and $r m t B$ has revealed a worldwide distribution among Enterobacteriaceae. Omitted single report, $a a c\left(6^{\prime}\right)-I b \quad(49.0 \%, 95 \%$ $\mathrm{CI}=36.4-61.6)$ was the most common $\mathrm{ARD}$, followed by $r m t B$ in our study. The similar results were reported in Spain [76]. In UK, armA was the most common, followed by $r m t C$ [77]. $R m t D$ has only been reported from South America [75], RmtA, rmtC, rmtD and rmtE were not found in our study.

So far, Qnr peptides, the aminoglycoside acetyltransferase variant $a a c\left(6^{\prime}\right)-I b-c r$ and plasmidic efflux pumps $Q e p A$ and $O q x A B$ are three known plasmid-mediated quinolone resistance mechanisms [78]. And PMQR have been mainly found in Enterobacteriaceae. aac(6')-Ib-cr was the most commonly reported PMQR followed by $q n r$ gene in Enterobacteriaceae in Mediterranean countries [81]. $q n r B$ was the most predominant family in Enterobacter cloacae non-susceptible to Ertapenem in North-Eastern France [79], the similar result was found in Spain [80]. Omitted the single report, aac(6')-Ib-cr was the most common PMQR in our study, followed by qnrB. Efflux pump qepA was identified in very few studies, no qep $A$ was found in this study. The prevalence of $o q x A B$ was relatively lower in Enterobacteriaceae of human origin than that of the animal or environmental sources [82], but oqxAB was reported in one article with a rate of $85.4 \%$ in our study.

This review was limited to the studies published in the English, Chinese languages and in peer-reviewed journals after 2009. Limiting our search was justified given the prevalence of antibiotic resistance determinants in CRE in recent years. In addition, publication bias had to be considered since results of negative finding may not have been published. Second, significant heterogeneity was found among included studies. Third, no standard test for antibiotic resistance determinants, the methods differed between studies. PCR/sequencing were most commonly adopted in these articles. Finally, many of studies identified the limited antibiotic resistant genes in CRE, which might have masked the real gene diversity in Mainland China. Therefore, the prevalence of antibiotic resistant genes in CRE in Mainland 
China requires further study.

\section{Conclusions}

The pooled prevalence of Carbapenemase, ESBL, AmpC-encoding, aminoglycoside resistance and PMQR genes in CRE clinical isolates of Mainland China were $73.3 \%, 81.8 \%$, $32.7 \%, 60.6 \%$ and $70.8 \%$, respectively. KPC-2, NDM-1, IMP-4, VIM-1 and $O X A-1$ were the

predominant type of a wide range of $K P C, N D M, I M P, V I M$ and $O X A$ variant genes. Among these, $K P C-2$ was the most common type of carbapenemase genes. $C T X-M-15$, $C T X-M-14$, $S H V-12$ and $T E M-1$ were the main type of $C T X-M, S H V$ and $T E M-1$ variant genes. TEM- 1 was the most common type of ESBL genes, while CMY-42 was the most prevalent AmpC-encoding gene. As for aminoglycoside resistance genes and PMQR genes, a $a c\left(6^{\prime}\right)-I b$ was the most common type in aminoglycoside resistance genes and $a a c\left(6^{\prime}\right)-I b-c r$ in PMQR genes, followed by $q n r B$. The current review provided information the prevalence and distribution pattern of carbapenemase, ESBL, AmpC, aminoglycoside resistances and PMQR genes among CRE clinical isolates in Mainland China. This information might help in guiding rational drug use in clinic and in designing measures that efficiently control the spread of these resistance determinants in Mainland China.

\section{References:}

[1] Willyard, C. The drug-resistant bacteria that pose the greatest health threats. Nature 2017, $543(7643), 15$.

[2] van Duin, D.; Doi, Y. The global epidemiology of carbapenemase-producing Enterobacter iaceae. Virulence 2017, 8(4), 460-469.

[3] Zhang, Y.; Wang, Q.; Yin, Y.; Chen, H.; Jin, L.; Gu, B.; Xie, L.; Yang, C.; Ma, X.; Li, H.; Li, W.; Zhang, X.; Liao, K.; Man, S.; Wang, S.; Wen, H.; Li, B.; Guo, Z.; Tian, J.; Pei, F.; Liu, L.; Zhang, L.; Zou, C.; Hu, T.; Cai, J.; Yang, H.; Huang, J.; Jia, X.; Huang, W.; Cao, B.; Wang, H. Epidemiology of Carbapenem-Resistant Enterobac teriaceae Infections: 
Report from the China CRE Network. Antimicrob Agents Chemother. 2018, 62(2)piie, 01882-17.

[4] Zhang, R.; Liu, L.; Zhou, H.; Chan, E.W.; Li, J.; Fang, Y.; Li, Y.; Liao, K.; Chen, S. Nationwide Surveillance of Clinical Carbapenem-resistant Enterobacteriaceae (CRE) Strains in China. EBioMedicine. 2017, 19, 98-106.

[5] Xiao, Y.H.; Wang, J.; Li, Y.; MOH National Antimicrobial Resistance Investigation Net. Bacterial resistance surveillance in China: a report from Mohnarin 2004-2005. Eur J Clin Microbiol Infect Dis 2008, 27(8), 697-708.

[6] Hu, F.P.; Guo, Y.; Zhu, D.M.; Wang, F.; Jiang, X.F.; Xu, Y.C.; Zhang, X.J.; Zhang, C.X.; Ji, P.; Xie, Y.; Kang, M.; Wang, C.Q.; Wang, A.M.; Xu, Y.H.; Shen, J.L.; Sun, Z.Y.; Chen, Z.J.; Ni, Y.X.; Sun, J.Y.; Chu, Y.Z.; Tian, S.F.; Hu, Z.D.; Li, J.; Yu, Y.S.; Lin, J.; Shan, B.; Du, Y.; Han, Y.; Guo, S.; Wei, L.H.; Wu, L.; Zhang, H.; Kong, J.; Hu, Y.J.; Ai, X.M.; Zhuo, C.; Su, D.H.; Yang, Q.; Jia, B.; Huang, W. Resistance trends among clinical isolates in China reported from CHINET surveillance of bacterial resistance, 2005-2014. Clin Microbiol Infect. 2016, 22 Suppl 1,S9-14.

[7] Logan, L.K.; Renschler, J.P.; Gandra, S.; Weinstein, R.A.; Laxminarayan, R.; Centers for Disease Control Prevention Epicenters Program. Carbapenem-resistant Enterobacteriaceae in children, United States, 1999-2012. Emerg Infect Dis 2015, 21, 2014-21.

[8] Montagnani, C.; Prato, M.; Scolfaro, C.; Colombo, S.; Esposito, S.; Tagliabue, C.; LoVecchio, A.; Bruzzese, E.; Loy, A.; Cursi, L.; Vuerich, M.; deMartino, M.; Galli, L.; Italian Society of Pediatric Infectious Diseases. Carbapenem-resistant Enterobacteriaceae infections in children: an Italian Retrospective Multicenter Study. Pediatr Infect Dis $J$ 2016, 35, 862-8.

[9] Nabarro, LEB.; Shankar, C.; Pragasam, A.K.; Mathew, G.; Jeyaseelan, V.; Veeraraghavan, B.; Verghese, V.P. Clinical and bacterial risk factors for mortality in children with carbapenem-resistant Enterobacteriaceae bloodstream infections in India. Pediatr Infect Dis J 2017, 36, e161-6.

[10] Patel, G.; Huprikar, S.; Factor, S.H.; Jenkins, S.G.; Calfee, D.P. Outcomes of carbapenem-resistant Klebsiella pneumonia infection and the impact of antimicrobial and 
adjunctive therapies. Infect Control Hosp Epidemiol 2008, 29(12), 1099-1106.

[11] Ivanov, I.; Sabtcheva, S.; Dobreva, E.; Todorova, B. Prevalence of carbapenemase genes among 16S Enterobacteriaceae isolate from cancer patients. Probl. Infect. Parasit. Dis 2014, 42(1), 10-13.

[12] Zasowski, E.J.; Rybak, J.M.; Rybak, M.J. The $\beta$-Lactams Strike Back: Ceftazidime-Avib actam. Pharmacotherapy 2015, 35(8), 755-70.

[13] Livermore, D.M.; Mushtaq, S.; Warner, M.; Zhang, J.C.; Maharjan, S.; Doumith, M.; Woodford, N. Activity of aminoglycosides,including ACHN-490, against carbapenem-resistant Enterobacteriaceae isolates. J Antimicrob Chemother. 2011, 66(1), 48-53.

[14] Zhanel, G.G.; Lawrence, C.K.; Adam, H.; Schweizer, F.; Zelenitsky, S.; Zhanel, M.; Lagacé-Wiens, PRS.; Walkty, A.; Denisuik, A.; Golden, A.; Gin, A.S.; Hoban, D.J.; Lynch, J.P3rd.; Karlowsky, J.A. Imipenem-relebactam and MeropenemVaborbac-tam: Two Novel Carbapenem- $\beta$-Lactamase Inhibitor Combinations. Drugs 2018, 78(1), 65-98.

[15] Petty, L.A.; Henig, O.; Patel, T.S.; Pogue, J.M.; Kaye, K.S. Overview of meropenem-vaborbactam and newer antimicrobial agents for the treatment of carbapenem-resistant Enterobacteriaceae. Infect Drug Resist. 2018, 11, 1461-1472.

[16] Li, Y.; Shen, H.; Zhu, C.; Yu, Y. Carbapenem-resistant Klebsiella pneumonia infections among ICU admission patients in central China: prevalence and prediction model. Biomed Res Int. 2019, 9767313.

[17] Higgins, J.P.; Thompson, S.G.; Deeks, J.J.; Altman, D.G. Measuring inconsistency in meta-analyses. BMJ 2003, 327, 557-60.

[18] Higgins, J.P.; Thompson, S.G. Quantifying heterogeneity in a meta-analysis. Stat Med. 2002, 21(11), 1539-58.

[19] Melsen, W.G.; Bootsma, M.C.; Rovers, M.M.; Bonten, M.J. The effects of clinical and statistical heterogeneity on the predictive values of results from meta-analyses. Clin Microbiol Infect. 2014, 20(2), 123-9.

[20] Zhao, D.; Zuo, Y.; Wang, Z.; Li, J. Characterize carbapenem-resistant Klebsiella pneumoniae isolates for nosocomial pneumonia and their Gram-negative bacteria neighbors in the respiratory tract. Mol Biol Rep 2019, 46(1),609-616. 
[21] Fang, L.; Lu, X.; Xu, H. Epidemiology and risk factors for carbapenem-resistant Enterobacteriaceae colonisation and infections: case-controlled study from an academic medical center in a southern area of China. Pathog Dis 2019, 77(4) pii, 5529390.

[22] Cai, Y.; Chen, C.; Zhao, M.; Yu, X.; Lan, K.; Liao, K.; Guo, P.; Zhang, W.; Ma, X.; He, Y.; Zeng, J.; Chen, L.; Jia, W.; Tang, Y.W.; Huang, B. High Prevalence of Metallo- $\beta$-Lactamase -Producing Enterobacter cloacae From Three Tertiary Hospitals in China. Front Microbiol. 2019, 10, 1610.

[23] Miao, M.; Wen, H.; Xu, P.; Niu, S.; Lv, J.; Xie, X.; Mediavilla, J.R.; Tang, Y.W.; Kreiswirth, B,N.; Zhang, X.; Zhang, H.; Du, H.; Chen, L. Genetic Diversity of Carbapenem-Resistant Enterobacteriaceae (CRE) Clinical Isolates From a Tertiary Hospital in Eastern China. Front Microbiol 2019, 9, 3341.

[24] Zhou, S.D.; Liu, C.L.; Sun, J.; Jia, L.; Li, Y.; Cao, H.Y.; Yan, H.J.; Sun, J. Resistance genes of carbapenem-resistant enterobacteriaceae in a hospital. Chin J Infect Control 2019, 18(6), 495-504

[25] Zhang, B.R.; Bi, R.R.; Kong, Z.Y.; Ma, P.; Gu, B. Drug resistance and genotypes of carbapenemase in carbapenem-resistant Enterobacteriaceae strains in Suqian region,China. Chin J Clin Lab Sci 2018, 9, 667-671.

[26] Bi, R.; Kong, Z.; Qian, H.; Jiang, F.; Kang, H.; Gu, B.; Ma, P. High Prevalence of blaNDM Variants among Carbapenem- Resistant Escherichia coli in Northern Jiangsu Province, China. Front. Microbiol 2018, 9, 2704.

[27] Jia, X.; Dai, W.; Ma, W.; Yan, J.; He, J.; Li, S.; Li, C.; Yang, S.; Xu, X.; Sun, S.; Shi, J.; Zhang, L. Carbapenem-Resistant E. cloacae in Southwest China: Molecular Analysis of Resistance and Risk Factors for Infections Caused by NDM-1-Producers. Front Microbiol 2018, 9, 658 .

[28] Gong, X.; Zhang, J.; Su, S.; Fu, Y.; Bao, M.; Wang, Y.; Zhang, X. Molecular characterization and epidemiology of carbapenem non-susceptible Enterobacteriaceae isolated from the Eastern region of Heilongjiang Province, China. BMC Infect Dis 2018, $18(1), 417$.

[29] Ye, Y.; Xu, L.; Han, Y.; Chen, Z.; Liu, C.; Ming, L. Mechanism for carbapenem resistance of clinical Enterobacteriaceae isolates. Exp Ther Med 2018, 15(1), 1143-1149. 
[30] Tian, X.; Sun, S.; Jia, X.; Zou, H.; Li, S.; Zhang, L. Epidemiology of and risk factors for infection with extended-spectrum $\beta$-lactamase-producing carbapenem-resistant Enterobacteriaceae: results of a double case-control study. Infect Drug Resist 2018, 11, $1339-1346$.

[31] Tian, D.; Pan, F.; Wang, C.; Sun, Y.; Zhang, H. Resistance phenotype and clinical molecular epidemiology of carbapenem-resistant Klebsiella pneumoniae among pediatric patients in Shanghai. Infect Drug Resist 2018, 11, 1935-1943.

[32] Dong, F.; Zhang, Y.; Yao, K.; Lu, J.; Guo, L.; Lyu, S.; Yang, Y.; Wang, Y.; Zheng, H.; Song, W.; Liu, G. Epidemiology of Carbapenem-Resistant Klebsiella pneumoniae Bloodstream Infections in a Chinese Children's Hospital: Predominance of New Delhi Metallo- $\beta$-Lactamase-1. Microb Drug Resist 2018, 24(2), 154-160.

[33] Zhang, X.; Chen, D.; Xu, G.; Huang, W.; Wang, X. Molecular epidemiology and drug resistant mechanism in Carbapenem-resistant Klebsiella pneumoniae isolated from pediatric patients in Shanghai, China. PLoS One 2018, 13(3), e0194000.

[34] Liu, L.; Feng, Y.; Tang, G.; Lin, J.; Huang, W.; Qiao, F.; Zong, Z. Carbapenem-resistant Isolates of the Klebsiella pneumoniae Complex in Western China: The Common ST11 and the Surprising Hospital-specific Types. Clin Infect Dis 2018, 67(suppl_2), S263-S265.

[35] Ding, H.; Wu, D.Y.; Jiang, L.L.; Li, A.F.; Li, G.X.; Zhao, Z.G. Characteristics of carbapenem -resistance Enterobacteriaceae infection in our hospital and genotypic analysis of carbapenemase genes. Chinese Journal of General Practice 2017, 15(9), $1549-1552$.

[36] Luo, Y.; Luo, R.; Ding, H.; Ren, X.; Luo, H.; Zhang, Y.; Ye, L.; Cui, S. Characterization of Carbapenem-Resistant Escherichia coli Isolates Through the Whole-Genome Sequencing Analysis. Microb Drug Resist 2018, 24(2), 175-180.

[37] Liang, W.J.; Liu, H.Y.; Duan, G.C.; Zhao, Y.X.; Chen, S.Y.; Yang, H.Y.; Xi, Y.L. Emergence and mechanism of carbapenem-resistant Escherichia coli in Henan, China, 2014. J Infect Public Health 2018, 11(3), 347-351.

[38] Yan, J.; Pu, S.; Jia, X.; Xu, X.; Yang, S.; Shi, J.; Sun, S.; Zhang, L. Multidrug Resistance Mechanisms of Carbapenem Resistant Klebsiella pneumoniae Strains Isolated in 
Chongqing, China. Ann Lab Med 2017, 37(5), 398-407.

[39] Rui, Z.; Dehua, L.; Hua, N.; Yue, F.; Yunmin, X.; L, J.H. Carbapenemase-producing Enterobacteriaceae in Yunnan province, China. Jpn J Infect Dis. 2016, 69(6), 528-530.

[40] Wang, Q.; Chen, H.; Zhang, Y.; Xian, H.; Liu, Y.; Li, H.; Chen, H.; Wang, X.; Wang, R.; Zhao, C.; Cao, B.; Wang, H. Risk factors and clinical outcomes for carbapenem-resistant Enterobacteriaceae nosocomial infections. Eur J Clin Microbiol Infect Dis 2016, $35(10), 1679-89$.

[41] Cheng, L.; Cao, X.L.; Zhang, Z.F.; Ning, M.Z.; Xu, X.J.; Zhou, W.; Chen, J.H.; Zhang, J.H.; Shen, H.; Zhang, K. Clonal dissemination of KPC-2 producing Klebsiella pneumoniae ST11 clone with high prevalence of oqxAB and rmtB in a tertiary hospital in China: results from a 3-year period. Ann Clin Microbiol Antimicrob 2016, 15, 1.

[42] Huang, W.Z.; Pan, X.N.; Zhang, Q.; Huang, C.Y.; Lao, S.X.; Ning, T. Research on genotypes of carbapenem-resistant enterobacteriaceae in children. Journal of GuangXi Medical University 2016, 33(2), 232-235.

[43] Yu, J.; Tan, K.; Rong, Z.; Wang, Y.; Chen, Z.; Zhu, X.; Wu, L.; Tan, L.; Xiong, W.; Sun, Z.; Chen, L. Nosocomial outbreak of KPC-2 and NDM-1-producing Klebsiella pneumoniae in a neonatal ward: a retrospective study. BMC Infect Dis 2016, 16(1), 563.

[44] Cui, L.; Zhao, J.; Lu, J. Molecular characteristics of extended spectrum $\beta$-lactamase and carbapenemase genes carried by carbapenem-resistant Enterobacter cloacae in a Chinese university hospital. Turk J Med Sci 2015, 45(6), 1321-8.

[45] PU, S.L.; Xu, X.Y.; Shi, J.; Zhang, L.P. Characterization of resistance genes and epidemiology of Carbapenem-non susceptible Enterobacter cloacae. J Third Mil Med Univ. 2015, 37(14), 1442-1448.

[46] Jin, Y.; Shao, C.; Li, J.; Fan, H.; Bai, Y.; Wang, Y. Outbreak of multidrug resistant NDM-1-producing Klebsiella pneumoniae from a neonatal unit in Shandong Province, China. PLoS One 2015, 10(3), e0119571.

[47] Li, B.; Xu, X.H.; Zhao, Z.C.; Wang, M.H.; Cao, Y.P. High prevalence of metallo- $\beta$-lactamase among carbapenem-resistant Klebsiella pneumoniae in a teaching hospital in China. Can J Microbiol.2014, 60(10), 691-5.

[48] Jian, Z.; Li, Y.; Liu, W.; Li, H.; Zhang, Y.; Li, Y.; Gu, X.; Peng, W. Detection of the novel 
IMP-38 among carbapenemase-producing Enterobacteriaceae in a university hospital, China.J Infect Dev Ctries. 2014, 8(8), 1044-8.

[49] Hu, L.; Zhong, Q.; Shang, Y.; Wang, H.; Ning, C.; Li, Y.; Hang, Y.; Xiong, J.; Wang, X.; Xu, Y.; Qin, Z.; Parsons, C.; Wang, L.; Yu, F. The prevalence of carbapenemase genes and plasmid-mediated quinolone resistance determinants in carbapenem-resistant Enterobacteriaceae from five teaching hospitals in central China. Epidemiol Infect 2014, 142(9), 1972-7.

[50] Zhang, C.M.; Xu, X.Y.; Pu, S.L.; Huang, S.; Sun, J.; Yang, S.; Zhang, L. Characterization of carbapenemases, extended spectrum beta-lactamases, quinolone resistance and aminoglycoside resistance determinants in carbapenem-non-susceptible Escherichia coli from a teaching hospital in Chongqing, Southwest China. Infect Genet Evol 2014, 27, 271-276.

[51] Liu, Y.; Wan, L.G.; Deng, Q.; Cao, X.W.; Yu, Y.; Xu, Q.F. First description of NDM-1-, KPC-2-, VIM-2- and IMP-4- producing Klebsiella pneumoniae strains in a single Chinese teaching hospital. Epidemiol Infect 2015, 143(2), 376-84.

[52] Zhou, T.; Zhang, X.; Guo, M.; Ye, J.; Lu, Y.; Bao, Q.; Chi, W. Phenotypic and molecular characteristics of carbapenem-non-susceptible Enterobacteriaceae from a teaching hospital in Wenzhou, southern China. Jpn J Infect Dis 2013, 66(2), 96-102.

[53] Dong, F.; Song, W.Q.; Xu, X.W.; Xu, H.; Liu, X.Q.; Chang, M. Analysis of carbapenemase genotypes in carbapenem-non susceptible Enterobacteriaceae strains isolated from pediatric patients. Chin J Infect Chemother 2013, 13(4), 270-273.

[54] Li, H.; Zhang, J.; Liu, Y.; Zheng, R.; Chen, H.; Wang, X.; Wang, Z.; Cao, B.; Wang, H. Molecular characteristics of carbapenemase-producing Enterobacteriaceae in China from 2008 to 2011: predominance of KPC-2 enzyme. Diagn Microbiol Infect Dis 2014, 78(1), $63-5$.

[55] Dai, W.; Sun, S.; Yang, P.; Huang, S.; Zhang, X.; Zhang, L. Characterization of carbapenemases, extended spectrum $\beta$-lactamases and molecular epidemiology of carbapenem-non-susceptible Enterobacter cloacae in a Chinese hospital in Chongqing. Infect Genet Evol 2013, 14, 1-7.

[56] Hu, F.; Chen, S.; Xu, X.; Guo, Y.; Liu, Y.; Zhu, D.; Zhang, Y. Emergence of 
carbapenem-resistant clinical Enterobacteriaceae isolates from a teaching hospital in Shanghai, China. J Med Microbiol 2012, 61(Pt 1), 132-6.

[57] Hu, Y.Y.; Cai, J.C.; Zhang, R.; Zhou, H.W.; Sun, Q.; Chen, G.X. Emergence of Proteus mirabilis harboring blaKPC-2 and qnrD in a Chinese Hospital. Antimicrob Agents Chemother 2012, 56(5), 2278-82.

[58] Huang, S.; Dai, W.; Sun, S.; Zhang, X.; Zhang, L. Prevalence of plasmid-mediated quinolone resistance and aminoglycoside resistance determinants among carbapeneme non-susceptible Enterobacter cloacae. PLoS One 2012, 7(10), e47636.

[59] Liu, Y.; Li, X.Y.; Wan, L.G.; Jiang, W.Y.; Li, F.Q.; Yang, J.H. Molecular characterization of the bla (KPC-2) gene in clinical isolates of carbapenem-resistant Klebsiella pneumoniae from the pediatric wards of a Chinese hospital. Can J Microbiol 2012, 58(10), 1167-73.

[60] Yang, Q.; Wang, H.; Sun, H.; Chen, H.; Xu, Y.; Chen, M. Phenotypic and genotypic characterization of Enterobacteriaceae with decreased susceptibility to carbapenems: results from large hospital-based surveillance studies in China. Antimicrob Agents Chemother 2010, 54(1), 573-7.

[61] Li, H.; Zhang, J.; Liu, Y.; Zheng, R.; Chen, H.; Wang, X.; Wang, Z.; Cao, B.; Wang, H. Molecular characteristics of carbapenemase-producing Enterobacteriaceae in China from 2008 to 2011: predominance of KPC-2 enzyme. Diagn Microbiol Infect Dis 2014, 78(1), $63-5$.

[62] SU, S.S.; Zhang, J.S.; Wang, Y.; Wang, Y.; Wang, Y.C,; Li, H.L.; Zhang, X.L. Mechanism of quinolone resistance of carbapenem-resistant enterobacteriaceae. Chin J Infect Control 2019 18(2), 99-104.

[63] Satlin, M.J.; Chen, L.; Patel, G.; Gomez-Simmonds, A.; Weston, G.; Kim, A.C.; Seo, S.K.; Rosenthal, M.E.; Sperber, S.J.; Jenkins, S.G.; Hamula, C.L.; Uhlemann, A.C.; Levi, M.H.; Fries, B.C.; Tang, Y.W.; Juretschko, S.; Rojtman, A.D.; Hong, T.; Mathema, B.; Jacobs, M.R.; Walsh, T.J.; Bonomo, R.A.; Kreiswirth, B.N. Multicenter Clinical and Molecular Epidemiological Analysis of Bacteremia Due to Carbapenem-Resistant Enterobacteriaceae (CRE) in the CRE Epicenter of the United States. Antimicrob Agents Chemother.2017, 61(4) pii, e02349-16. 
[64] Patel, G.; Bonomo, R.A. "Stormy waters ahead": global emergence of carbapenemases. Front Microbiol.2013, 4, 48.

[65] Nordmann, P.; Naas, T.; Poirel, L. Global spread of Carbapenemase-producing Enterobacteriaceae. Emerg Infect Dis.2011, 17(10), 1791-8.

[66] Ito, H.; Arakawa, Y.; Ohsuka, S.; Wacharotayankun, R.; Kato, N.; Ohta, M. Plasmid-mediated dissemination of the metallo-beta -lactamase gene blaIMP among clinically isolated strains of Serratia marcescens. Antimicrob Agents Chemother.1995, $39(4), 824-9$

[67] Wang, J.T.; Wu, U.I.; Lauderdale, T.L.; Chen, M.C.; Li, S.Y.; Hsu, L.Y.; Chang, S.C. Carbapenem -nonsusceptible Enterobacteriaceae in Taiwan. PLoS One.2015, 10(3), e0121668

[68] Walsh, T.R.; Toleman, M.A.; Poirel, L.; Nordmann, P. Metallo-beta-lactamases: the quiet before the storm? Clin Microbiol Rev 2005, 18(2), 306-25.

[69] Stewart, A.; Harris, P.; Henderson, A.; Paterson, D. Treatment of infections by OXA-48Producing Enterobacteriaceae. Antimicrob Agents Chemother 2018, 62(11) pii, e01195-18.

[70] Wang, Q.; Wang, X.; Wang, J.; Ouyang, P.; Jin, C.; Wang, R.; Zhang, Y.; Jin, L.; Chen, H.; Wang, Z.; Zhang, F.; Cao, B.; Xie, L.; Liao, K.; Gu, B.; Yang, C.; Liu, Z.; Ma, X.; Zhang, X.; Man, S,; Li, W.; Pei, F.; Xu, X.; Jin, Y.; Ji, P.; Wang, H. Phenotypic and Genotypic Characterization of Carbapenem-resistant enterobacteriaceae: Data from a Longitudinal Large-scale CRE Study in China (2012-2016). Clin Infect Dis 2018, 67(suppl_2), S196-S205

[71] Sheng, W.H.; Badal, R.E.; Hsueh, P.R.; SMART Program. Distribution of extended-spectrum $\beta$-lactamases, AmpC $\beta$-lactamases and carbapenemases among Enterobacteriaceae isolates causing intra-abdominal infections in the Asia-Pacific region: results of the study for monitoring antimicrobial resistance trends (SMART). Antimicrob Agents Chemother 2013, 57(7), 2981-8.

[72] Jean, S.S.; Hsueh, P.R.; SMART Asia-Pacific Group. Distribution of ESBL, AmpC $\beta$-lactamases and carbapenemases among Enterobacteriaceae isolates causing intra-abdominal and urinary tract infections in the Asia-Pacific region during 2008-14: 
results from the Study for Monitoring Antimicrobial Resistance Trends (SMART). $J$ Antimicrob Chemother. 2017, 72(1), 166-171.

[73] Wilson, H.; Török, M.E. Extended-spectrum $\beta$-lactamase-producing and carbapenemaseproducing Enterobacteriaceae. Microb Genom. 2018, 4(7).

[74] Philippon, A.; Arlet, G.; Jacoby, G.A. Plasmid-determined AmpC-type ß-lactamases. Antimicrob. Agents Chemother 2002, 46, 1-11.

[75] Ramirez, M.S.; Tolmasky, M.E. Aminoglycoside modifying enzymes. Drug Resist. Updat 2010, 13, 151-171.

[76] Fernández-Martínez, M.; RuizDelCastillo, B.; Lecea-Cuello, M.J.; Rodríguez-Baño, J.; Pascual, Á.; Martínez-Martínez, L.; Spanish Network for the Research in Infectious Diseases (REIPI) and the Spanish Group for Nosocomial Infections (GEIH). Prevalence of Aminoglycoside -Modifying Enzymes in Escherichia coli and Klebsiella pneumoniae Producing Extended Spectrum $\beta$-Lactamases Collected in Two Multicenter Studies in Spain. Microb Drug Resist. 2018, 24(4), 367-376.

[77] Taylor, E.; Sriskandan, S.; Woodford, N.; Hopkins, K.L. High prevalence of 16S rRNA methyltransferases among carbapenemase-producing Enterobacteriaceae in the UK and Ireland. Int J Antimicrob Agents 2018, 52(2), 278-282.

[78] Jacoby, G.A.; Strahilevitz, J.; Hooper, D.C. Plasmid-mediated quinolone resistance. Microbiol Spectr. 2014, 2(5).

[79] Guillard, T.; Cholley, P.; Limelette, A.; Hocquet, D.; Matton, L.; Guyeux, C.; Lebreil, A.L.; Bajolet, O.; Brasme, L.; Madoux, J.; Vernet-Garnier, V.; Barbe, C.; Bertrand, X.; de Champs On Behalf Of CarbaFrEst Group C. Fluoroquinolone Resistance Mechanisms and population structure of Enterobactercloacae non-susceptible to Ertapenem in North-Eastern France. Front Microbiol. 2015, 6, 1186.

[80] Machuca, J.; Agüero, J.; Miró, E.; Conejo, MDC.; Oteo, J.; Bou, G.; González-López, J.J.; Oliver, A.; Navarro, F.; Pascual, Á.; Martínez-Martínez, L. Prevalence of quinolone resistance mechanisms in Enterobacteriaceae producing acquired AmpC $\beta$-lactamases and/or carbapenemases in Spain. Enferm Infecc Microbiol Clin. 2017, 35(8), 487-492.

[81] Yanat, B.; Rodríguez-Martínez, J.M.; Touati, A. Plasmid-mediated quinolone resistance in Enterobacteriaceae: a systematic review with a focus on Mediterranean countries. Eur $J$ 
Clin Microbiol Infect Dis 2016, 36(3), 421-435.

[82] Chen, X.; Zhang, W.; Pan, W.; Yin, J.; Pan, Z.; Gao, S.; Jiao, X. 2012.Prevalence of qnr, aac $\left(6^{\prime}\right)-\mathrm{Ib}-\mathrm{cr}$, qepA, and oqx $\mathrm{AB}$ in Escherichia coli isolates from humans, animals, and the environment. Antimicrob Agents Chemother 2012, 56(6), 3423-7. 